\title{
Peertechz
}

\section{Research on blockchain in the integrated application of medical services}

\section{Chin-Ling Chen*}

Full Professor, Department of Computer Science and Information Engineering, Chaoyang University of Technology, 168, Jifeng E. Rd., Wufeng District, Taichung, 41349, R.O.C, Taiwan
Received: 06 May, 2021

Accepted: 11 May, 2021

Published: 12 May, 2021

*Corresponding author: Chin-Ling Chen, Full Professor, Department of Computer Science and Information Engineering, Chaoyang University of Technology, 168, Jifeng E. Rd., Wufeng District, Taichung, 41349, ROC, Taiwan, Tel: +886-919668805;

E-mail: clc@mail.cyut.edu.tw

ORCID: https://orcid.org/0000-0002-4958-2043

https://www.peertechzpublications.com

Check for updates
«The technology that is most likely to change the corporate world in the next ten years is not social networks, big data, cloud computing, robots; not even artificial intelligence, but blockchain.» «Blockchain Revolution: How the Technology Behind Bitcoin Is Changing Money, Business, and the World», ranked among the top 50 management thinkers in the world and author of the book «Blockchain Revolution» Tang. Don Tapscott said so. The main characteristics of blockchain technology are decentralization, high credibility, versatility, transparency, autonomy, non-modifiable information, anonymity, traceability and irreversibility, intelligence, and reward mechanism $[1,2]$ and other characteristics. The technology of the blockchain is essentially a decentralized and open and transparent distributed database maintained by the collective. It has the characteristics of reliability and high confidentiality and has a good prospect in effectively solving the trust problem between the parties to the transaction. Credit is the basis for the production and maintenance of social relations between people and organizations. At present, people mainly use regulations, systems, laws, contracts, etc. to restrict credit issues. These methods cannot solve credit issues due to many subjective factors.

The decentralization of the blockchain allows all users who join the blockchain to participate in the verification of the authenticity of their data and discards the shortcomings of a single authentication center in the traditional authentication system. The essence of the blockchain is technology. The decentralization of the blockchain refers more to the "multicentralized authentication system" of the blockchain, rather than the "non-centralization"; the openness of the blockchain refers to the blockchain resources and management belong to all nodes that join the system, and they cover the subjects outside the blockchain system; the autonomy of the blockchain means that the blockchain is maintained by its system nodes, and its data certification mechanism is controlled by the computer. It is made through agreement and realized without human intervention; each node that joins the blockchain records the blockchain data in a distributed manner, which ensures that the data cannot be modified. The identities are all expressed through the key sequence value issued by them. This anonymous identity information exchange mode can effectively realize the privacy protection of nodes.

Block refers to the packet that records all transactions over some time. Here, the definition of a transaction is broad, from trading goods, assets, willingness, to deliver results and progress. Once the transaction-related parties agree with the final result, the transaction records generated in the process will be packaged and sealed. From then on, no change is allowed, and all blocks are connected in time order, extending endlessly. The blockchain is a "national paparazzi" mechanism to strengthen the function of supervision. The technology of blockchain is characterized by "decentralization", "openness" and "transparency". In addition, it is a set of open technology, which can be used by everyone. Therefore, it has been expanded to be defined as the "king of destruction" who changes the rules of all trading games. For example, all behaviors involving "trading" can not avoid its impact from business, intermediary, science and technology, lawyers, even food safety inspection, voting, capital security, etc. Judging from the current situation, the general trend of blockchain has become difficult. It promises us a new trading mode of sharing, credibility, and low cost. Anyone or enterprise can change itself into a trust machine and join the trust economic circle as long as they agree with it. A simple change in the way of accounting reorganizes the trust relationship between human beings, and a new business revolution will start from now on. Blockchain is a new 
technology to change the way of "accounting". It allows each account of each node in the transaction process to be recorded transparently, economically, and safely. Therefore, the official name of blockchain is "distributed ledger technology". Its real contribution is not limited to the financial industry. It may change the trading behavior of all human beings.

Blockchain technology includes hash algorithm, digital signature, timestamp technology, workload proof mechanism, etc. These technologies can ensure the source, time, and involved subject of data and prove its authenticity and reliability while encrypting and protecting blockchain data. Each node in the blockchain system does not need to master the technical details in the field of computer information security but only needs to understand the specific system operation specifications. At the same time, it is open and transparent. It realizes the openness of network to node application and combines information security technology with economic management. It is the greatest innovation in the field of human credit.

Professor Klaus Schwab, the founder of the World Economic Forum (WEF), predicted that blockchain will drive the fourth industrial revolution of mankind after the invention of steam engines, electricity, and computers. Andrey Sharov, vice chairman of Sberbank, predicted that blockchain technology will make banks disappear in 10 years! Since the invention of Bitcoin ushered in the beginning of a new era of finance and economy, the fourth industrial revolution has also kicked off. Blockchain is based on decentralized ledger technology, which can realize data privacy protection, safe storage, and non-repudiation proof. Since its inception in 2009, blockchain technology has gradually been recognized by people and has been valued and studied in various industries. At present, academia and industry have made many improvements to its technology and applications based on the principles of Bitcoin blockchain technology, forming blockchain products in different application fields.

With the development of medical technology, medical information becomes more and more important in terms of patient identity background, past medical history, and records of medical payment status. Medical data may be a person's most private data, but due to network operation errors or hacking attacks, in the past, these personal private data have been exposed to a large-scale risk. In any case, how to protect these medical data and ensure the privacy of patients has become a topic worthy of research.

At present, there are many pieces of blockchain research, but relatively few researches in the medical field. The main directions are medical information protection, medical payment, medical data application, medical data storage and sharing, medical information transaction, predictive analysis, etc. The rapid development of blockchain technology has attracted widespread attention from government departments, financial institutions, enterprises, and capital markets. Lvan proposed a method to securely store patient medical records based on blockchain [3]. Shrier, et al. proposed to use the OPAL/ Enigma encryption platform of the Massachusetts Institute of Technology in the United States, with blockchain technology to create a secure environment for storing and analyzing medical data [4]. Kuo, et al. used blockchain private chain network technology to create a cross-institutional medical health prediction model [5], and Ekblaw et al. proposed a novel decentralized electronic medical record management system [6]. Some studies have evaluated the use of blockchain to store electronic medical records $[7,8]$ and health-related matters.

However, the above references mainly focus on the security issues that need to be discussed in the application of blockchain technology in the integration and application of medical services. They only propose some conceptual and architectural concepts, and rarely involve the details of real security agreements. In daily life, Attacks by hackers are increasing day by day. How to protect the confidential information transmitted on the network and stored in the system from the threat of illegal acts such as theft, tampering, forgery, and destruction by illegal personnel is important for information-related personnel. task. Therefore, how to ensure the information security of the application of information technology in digital life is a top priority. In the future, we look forward to more articles about protecting information security.

\section{References}

1. Li X, Jiang P, Chen $T$, Luo $X$, Wen Q (2018) A survey on the security of blockchain systems. Future Generation Computer Systems 107: 841-853. Link: https://bit.ly/33wvlfk

2. Lin IC, Liao TC (2017) A Survey of Blockchain Security Issues and Challenges. International Journal of Network Security 19: 653-659. Link: https://bit.ly/3f8Pgfo

3. Lvan D (2016) Moving toward a blockchain-based method for the secure storage of patient records. Link: https://bit.ly/3tDyZV1

4. Shrier AA, Chang A, Diakun-thibault N, FornI L, Landa F, et al. (2016) Blockchain and Health IT: Algorithms, Privacy, and Data. Link: https://bit.ly/3fcJUzw

5. Kuo TT, Hsu CN, Ohno-machado L (2016) ModelChain: decentralized privacypreserving healthcare predictive modeling framework on private blockchain networks. Link: https://bit.ly/3y1H5Kr

6. Ekblaw A, Azaria A, Halamka JD, Lippman A (2016) A Case Study for Blockchain in Healthcare: "MedRec" prototype for electronic health records and medical research data, In Proceedings of the 2016 IEEE of International Conference on Open and Big Data 25-30. Link: https://bit.ly/3vXUFwq

7. Yuan B, Lin W, Mcdonnell C (2016) Blockchains and electronic health records.

8. Witchey NJ (2015) Healthcare Transaction Validation Via Blockchain Proof-ofWork, Systems and Methods: U. S. Patent.

Copyright: (c) 2021 Chen CL. This is an open-access article distributed under the terms of the Creative Commons Attribution License, which permits unrestricted use, distribution, and reproduction in any medium, provided the original author and source are credited. 